\title{
Cellulose Whiskers Derived from Banana Pseudo-Stem as Potential Reinforcement Filler for Tyre Tread Compounds
}

\author{
T.A.R.W.M.M.C.G. Bandara ${ }^{1, *}$, H.G.I.M. Wijesinghe' ${ }^{1}$, A.M.W.K. Senevirathna ${ }^{1}$, Thusitha N.B. Etampawala ${ }^{2}$
}

${ }^{1}$ Department of Export Agriculture, Uva Wellassa University of Sri Lanka, Badulla, Sri Lanka.

${ }^{2}$ Department of Polymer Science, Faculty of Applied Sciences, University of Sri Jayewardenepura, Nugegoda, Sri Lanka.

\section{AR T I C L E D E T A I L S}

\section{Article history:}

Received 23 September 2019

Accepted 10 October 2019

Available online 15 October 2019

\section{Keywords:}

Cellulose Whiskers

Agro-Industrial Waste

Banana Pseudo-Stem

\begin{abstract}
A B S T R A C T
In this study, cellulose fibre was extracted from banana pseudo-stem and converted into cellulose whiskers (CWs) with high-pressure defibrillation method. The CWs were characterized using FTIR, XRD and the results conform the structure of cellulose. XRD studies showed that the percentage crystallinity of bleached fibres is about 93\%. The particle size analysis showed a bimodal distribution for CWs where approximately $21 \%$ of the sample has average size of $110 \mathrm{~nm}$. The rubber compounds were prepared according to a general tyre tread formulation while incorporating the purified CWs in diluted centrifuged latex (NR) followed by converting them into rubber sheets to produce cellulose whiskers/natural rubber $\mathrm{CW} / \mathrm{NR}$ composite. Meanwhile, the control was prepared without incorporating CW in the diluted centrifuged latex. The lowest Mooney viscosity and the highest stress relaxation coefficient of CW/NR composites ensured higher processability. Curing characteristics of the compounds were evaluated at $120^{\circ} \mathrm{C}$ and physical properties were evaluated on par to the ASTM standards. The highest cure rate and better scorch time were observed in CW/NR composite. Most of the physical properties were superior. In overall, it is obvious that cellulose whiskers have a potential to use as reinforcing material for natural rubber tyre tread compounds.
\end{abstract}

\section{Introduction}

Natural rubber latex is a renewable biopolymer, tapped from Hevea brasiliensis with a wide spectrum of applications, which can be gained after vulcanization. However, vulcanization itself cannot gain the required properties in a respected rubber product. Therefore, it is usually modified for further increment of its targeted uses. Nevertheless, natural rubber is an indispensable and very important material in both industrial and household uses while performing as an outstanding material for better tensile properties, good crack growth resistance due to its strain induced crystallization [1]. With respect to achieve the intended properties, reinforcement of a polymer composite material is highly considered. According to Bokobza and Chauvin [2], it has been suggested that reinforcement of the elastomeric compound was defined as the elevation of elastic modulus and elongation at break by addition of particular filler ingredients.

Reinforcement of elastomers is commonly done by the carbon black (CB) and silica in the rubber industry and it is said that any finely divided particles can enhance the tensile properties where chemical and physical bonds fixes the filler in the polymer matrix and allows the stress delocalization through facial slippage [2]. Comparatively, with gum rubber (without any filler), CB filled rubber composites are superior in high modulus, strength and abrasion resistance. However, with the green concepts, the controversial argument is there against CB and also it is said that the effect of the CB on such composites is not negligible [3] and cannot be replaced by any other existing low-cost fillers. Silica is another filler which is more capable in reducing the heat buildup and possess low rolling resistance which makes it indispensable in rubber composites, especially in tyre manufacturing. However, high density $\left(2.5 \mathrm{~g} / \mathrm{cm}^{3}\right)$ of silica increases the density of composites, longer the processing time and higher the energy requirement of mixing [4]. Not only that, but also a study done by Kirushanthi et al. [5] has suggested that the silica derived from rice husk ash, another agricultural waste, can comparatively improve the crumb rubber-filler interaction to provide better reinforcement. Kondarage et al. [6] has shown that fired waste ceramics can be incorporated with natural rubber and obtained substantial improvement of mechanical properties. Also, short natural fibres and clay materials are used as green fillers in rubber manufacturing [7].

According to the study done by Bras et al. [8], cellulose have been extracted from bleached sugarcane bagasse craft pulp and have added the cellulose whiskers as the reinforcing elements into NR without any surface modification, and the effect of loading of cellulose whiskers has been studied. Significant improvement of Young's modulus and tensile strength have been observed as a result of adding cellulose whiskers to the rubber matrix especially at high whiskers loading levels. Also, according to the study of Pasquini et al. [9], they have succeeded in obtaining cellulose from cassava bagasse, a byproduct of cassava starch production where sulfuric acid hydrolyzation treatment has been practiced. High aspect ratio as well as good physical properties after NR compounding has been observed after dynamic mechanical tests. And the storage tensile modulus has been increased significantly upon the addition of cellulose. Positive properties of tensile strength, elongation modulus, storage modulus, and thermal stability have been observed [10], by incorporating bamboo based cellulose whiskers derived from bamboo pulp wastes of paper production. Also, it is succeeded in separating cellulose from agricultural wastes like straw and tunicin and they have succeeded in using the same cellulose as reinforcement in polymer composites. It has been reported that cellulose fibres in both nano and micro sizes can be used to replace the man made synthetic fibres or any other materials which can supposed to be harmful to the environment also it can reduce the over dependence of petroleum based treacherous reinforcing materials like CB [11].

Currently, natural plant fibres such as kenaf, jute, coir, rice husk, banana, bamboo, sisal, etc. are predominantly available in developing countries such as Malaysia, Indonesia, Thailand, and other Asian countries $[12,13]$. Indeed, natural cellulosic fibres are rapidly emerging as novel low-cost materials for several industrial applications while large volumes of cellulosic waste materials originating from agricultural and industrial activities are often considered as worthless staffs [14].

In the plants fibres, cellulose is available in its very natural form and often with other components such as hemicellulose, lignin, and pectin, etc. Altogether, the source of the cellulose is lignocellulosic material in wood [15].

Among the above stated plants, banana is recorded as one of the oldest cultivated plants [13] in which pseudo stem is commonly known as trunk which is fibrous in nature and enriched in cellulose content [16] are left 
behind after harvesting the ripened fruit bunches [17]. Those pseudo stems are currently used only for the compost preparation or some time burnt resulting in the environmental pollution. The outer sheaths of pseudo-stem are composed of the coarsest fibre which are very brittle and can be broken at a slightest tension. Since the innermost sheaths contain pulpy matter only the intermediate sheaths have been utilized for obtaining banana pseudo-stem fibres. Extraction of banana fibres from the pseudo stem can be done manually as well as mechanically using banana fibre extractor machines or it can be also done in laborious manual processes [16]

According to Cherian et al. [18], based on the cellulose derived from banana pseudo stem fibre, they suggested that cellulose fibre has gain much attraction due to its large surface to volume ratio, high surface area, good mechanical properties including a high Young's modulus, high tensile strength and a very low coefficient of thermal expansion, and formation of highly porous mesh as compared to other commercial fibres. Moreover, it reveals that banana fibre cellulose can be chemically extracted and purified by using chemical methods. These raw banana fibre can be used to synthesis cellulose whiskers that can be used as the reinforcing filaments in rubber compounds without any tedious surface modifications [8].

In this work, the major objective was to extract cellulose from banana pseudo-stem and utilize the derived cellulose in rubber tyre tread compound preparation. These banana fibres were undergone high pressure defibrillation followed by rigorous chemical treatments.

\section{Experimental Methods}

For this study, manually extracted dried banana fibres, analytical grades of sodium hydroxide, acetic acid, sodium hypochlorite and oxalic acid were used.

\subsection{Banana Fibre Extraction}

Banana fibres were manually extracted after boiling the banana pseudo-stem sheaths in an Aluminium container in the presence of wood ash for 2 hours and the mucilaginous substances were removed using a wire brush and the banana pseudo stem fibres were extracted. For that the middle most sheaths were only taken for the boiling purpose. The extracted fibres were sun dried to reduce the moisture content of the fibre and then the dried fibres were packed in a sealed transparent polythene bag.

\subsection{Cellulose Whiskers Preparation}

Firstly, the dried banana fibres were ground using a high-speed universal disintegrator and sieved through $500 \mu \mathrm{m}$ mesh. Secondly, during the steam exploding, ground banana fibres were treated in $2 \% \mathrm{NaOH}$ (fibre to liquor ratio $1: 10$ ) in an autoclave under $20 \mathrm{lb}$ for one hour. Then the pressure was released immediately. After, treated fibre was allowed to drain the water followed by rigorous washing with distilled water until it was got rid of alkalinity. Thirdly, in order to prepare the steam exploded bleached fibres, pretreated fibres were bleached using $\mathrm{NaOH}$ solution (27 $\mathrm{g}$ in 1 liter of water), acetic acid solution (78.8 g in 1 liter of water) and a mixture of 1:3 sodium hypochlorite solution repeatedly for six repetitions. Then the treated fibres were washed rigorously in distilled water. Fourthly, the treated fibres were treated in $11 \%$ oxalic acid in autoclave until it took $20 \mathrm{lb}$ and the pressure was released immediately. Then the pressure in the autoclave was allowed to obtain $20 \mathrm{lb}$ and the medium was allowed to be there for 15 minutes and the process was repeated for 8 times. Then the fibres were taken out and they were washed using distilled water until the washings does not decolourized the $\mathrm{KMnO}_{4}$ solution. And finally, fibres were suspended in distilled water and it was emulsified at $8000 \mathrm{rpm}$ for 4 hours using a Silverson High Shear Mixer (L4RT) to prepare the cellulose whiskers [18].

\subsection{Fibre Characterization}

FTIR spectrometer (Bruker, Alpha-T, German) was used to characterize the fibre samples from raw banana fibre, alkaline treated banana fibre and the bleached banana fibres using a deuterated triglycine sulphate (DTGS) as a detector. It was interfaced to a computer operating under Windowsbased, and connected to OPUS (Version 7.5) software. FTIR spectra were collected in frequency $4000-500 \mathrm{~cm}^{-1}$ by co-adding 64 scans and at resolution of $4 \mathrm{~cm}^{-1}$. All spectra were rationed against a background of air spectrum. Resulted fibres from each step was ground and mixed with dehydrated $\mathrm{KBr}$ to prepare pastilles.

Rigaku Ultima IV-X-Ray Diffractometer was used to investigate the relative crystallinities of steam exploded banana fibre, bleached fibre as well as raw banana fibres. The percentage crystallinity was determined using a powder X-ray diffraction method (PXRD). Percentage crystallinity $\left(C_{I}\right)$ was measured where $I_{002}$ is the maximum intensity (in arbitrary units) of the 0,0,2 lattice diffraction and $I_{a m}$ is the intensity of diffraction in the same units at the nearest depression.

$$
C_{I}=\frac{I_{002}-I_{a m}}{I_{002}} \times 100
$$

Particle size was analyzed using a Malvern Particle Size Analyzer (Zetasizer Nano ZS). There, the bleached cellulose aqueous medium was investigated considering the refractive index of water as 1.333 .

\subsection{Rubber Compounding}

In dry rubber compounding, $3 \mathrm{phr}$ of the CWs were mixed with diluted centrifuged latex up to $30 \%$ dry rubber content (DRC) and the raw rubber sheets were prepared. According to Tables 1-4, CW/NR composite and the control were prepared. Raw rubber sheets were evaluated for their Mooney viscosities using the Mooney Viscometer (MV 2000, Alpha Technologies, USA) using a large rotor at $100{ }^{\circ} \mathrm{C}$ under $\mathrm{ML}(1+4) 100{ }^{\circ} \mathrm{C}$ test condition. Following a general tread formulation, both $1^{\text {st }}$ stage and the $2^{\text {nd }}$ stage compounds of control and CW/NR composite were prepared.

Table 1 First stage compound formulation

\begin{tabular}{ll}
\hline Ingredient & Weight (g) \\
\hline Rubber with 3 phr of CWs & 781 \\
CB & 356 \\
Activator System & 49 \\
Protection System & 12 \\
\hline
\end{tabular}

Protection System

Table 2 Second stage compound formulation

\begin{tabular}{ll}
\hline Ingredient & Weight (g) \\
\hline $1^{\text {st }}$ Stage Compound & 1200 \\
Curing System & 17 \\
\hline
\end{tabular}

Table 3 First stage compound formulation of the control compound

\begin{tabular}{ll}
\hline Ingredient & Weight $(\mathrm{g})$ \\
\hline Rubber without 3 phr of CWs & 773 \\
CB & 363 \\
Activator System & 50 \\
Protection System & 12 \\
\hline
\end{tabular}

Table 4 Second stage compound formulation of the control sample

\begin{tabular}{ll}
\hline Ingredient & Weight $(\mathrm{g})$ \\
\hline $1^{\text {st }}$ Stage Control Compound & 1200 \\
Curing System & 17 \\
\hline
\end{tabular}

Curing characteristics of the second stage compounds were measured using an ODR Rheometer (Alpha Technologies, USA) at $150{ }^{\circ} \mathrm{C}$ for 30 minutes of testing time and the physical and mechanical properties were measured following ASTM standards.

Density of compounds was measured by electronic densimeter MD3003 in accordance with ASTM D-297 standard. Resistance to indentation (Hardness) was measured in accordance with ASTM D-2240 standard Evaluation of tensile strength, elongation and modulus of the vulcanizates were measured according to ISO 37-1994 standard. Evaluation of tear strength of rubber was measured in accordance with ASTM D-624-86 standard. Determination of abrasion resistance was measured on par with the volume loss of the rubber vulcanizate in accordance with DIN 53516 standard. In evaluation of rebound resilience, it was measured in accordance with ASTM D-2632 standard

\section{Results and Discussion}

FTIR spectra of raw banana fibre and its derivatives have been represented from Figs. 1-4.

According to the Fig. 1, at the left of the FTIR spectrum, the peak which arises from the $3400 \mathrm{~cm}^{-1}$ area is due to stretching of $\mathrm{OH}$ bond of absorbing moisture [19]. Next to this region is the $\mathrm{C}-\mathrm{H}$ bonding which appears between $3000-2800 \mathrm{~cm}^{-1}$ region. Then the $2915 \mathrm{~cm}^{-1}$ peak is due to the alkyl C-H stretch functional groups mostly from the cellulose and a bit from the hemicellulose presenting in the purified cellulose. The peak at $1635 \mathrm{~cm}^{-1}$ is due to amide $\mathrm{C}=0$ Stretching because of the dissolution of hemicellulose during the steam explosion and bleaching while the amide $\mathrm{C}=0$ Stretching of the remaining pectin gives the same peak having methyl 
esters and carboxylic acids [20]. In the Figs. 2 and 3, this peak is absent or less due to the partial de-esterification process happens in the process of alkaline treatment and the bleaching. The peaks at $1629 \mathrm{~cm}^{-1}-1630 \mathrm{~cm}^{-1}$ is due to the alkenyl $\mathrm{C}=\mathrm{C}$ stretching vibration, the indicative of the presence of lignin. The absence of the peak conforms that this sample is not contaminated with lignin. In the Fig. 1 , the bands in the region of 1250 $1056 \mathrm{~cm}^{-1}$ wavenumber involving the $\mathrm{C}-\mathrm{O}$ stretching vibrations of aliphatic primary and secondary alcohols in cellulose, hemicellulose, lignin, and extractives [18].

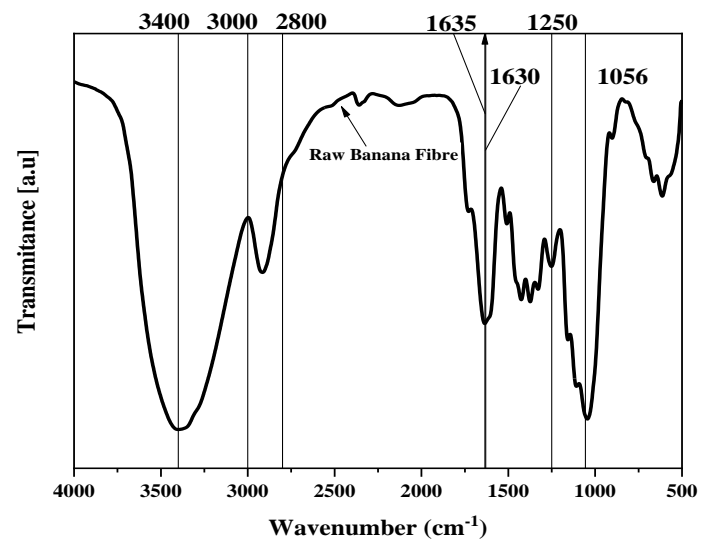

Fig. 1 FTIR spectra of the raw banana fibre

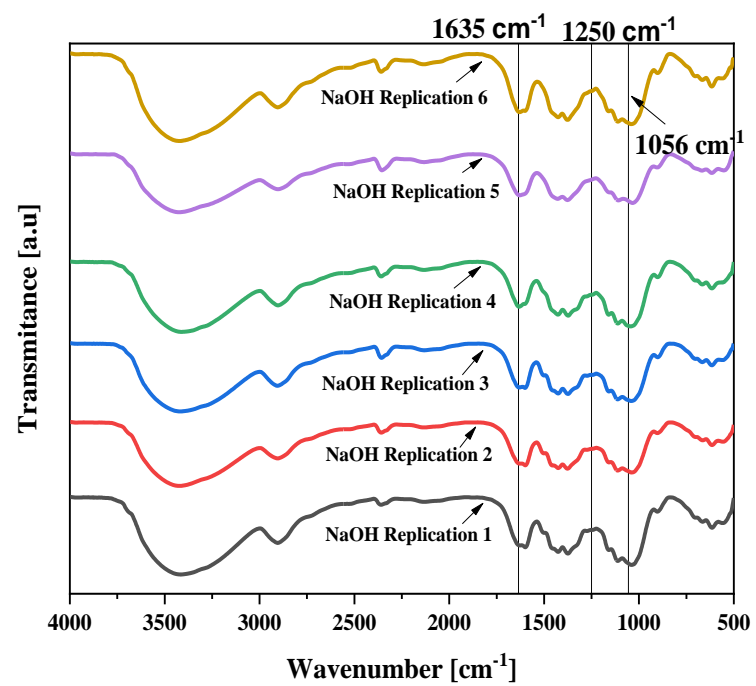

Fig. 2 FTIR spectra for six-times purification of $\mathrm{BF}$ with $\mathrm{NaOH}$

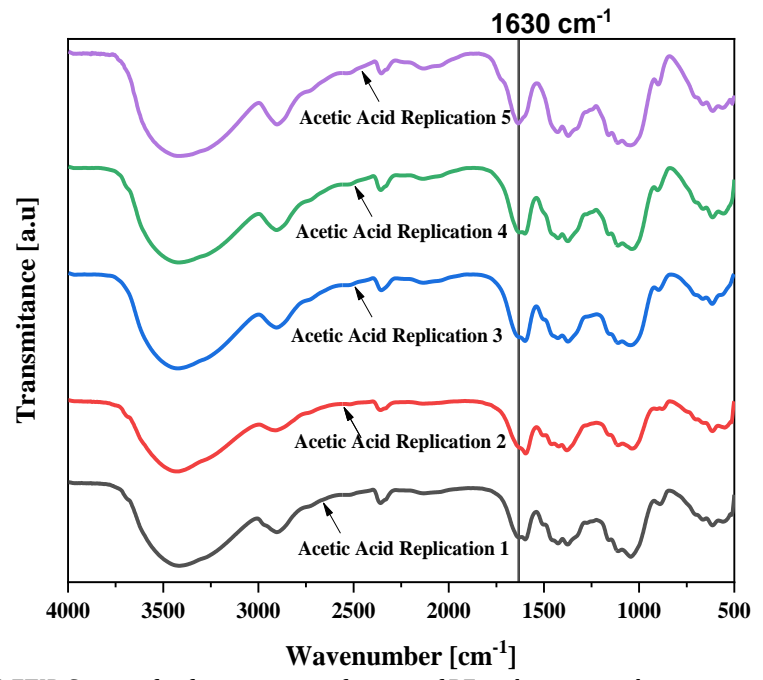

Fig. 3 FTIR Spectra for five-times purification of BF with acetic acid

According to the Fig. 4, the intensity of the peak at $1250 \mathrm{~cm}^{-1}$ is sharply weakened after bleaching treatment because of the removal of the hemicellulose material. The peak area of the peaks due to the lignin components is found to be decreased from raw fibre to the bleached fibres. This proves that most of the lignin components were dissolved during steam explosion and on further bleaching processes [20].

https://doi.org/10.30799/jacs.214.19050302

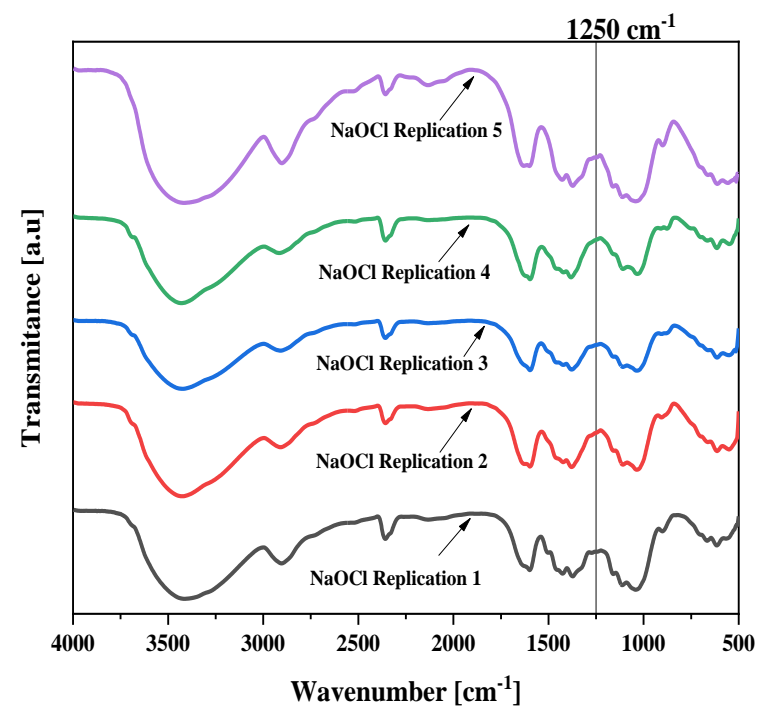

Fig. 4 FTIR spectra for five-times purification of $\mathrm{BF}$ with $\mathrm{NaOCl}$

According to the Fig. 5, banana fibres reveal a semi crystalline nature [21]. It was vividly clear that each and every purification step were able to improve the crystallinity except $\mathrm{NaOH}$ treatment. According to the diffractogram, it shows a very little crystallinity while the majority was in amorphous phase [18]. Raw banana fibres showed $81.53 \%$ of the percentage crystallinity at $2 \theta$ value of $22.23^{\circ}$. However, with the alkaline treatment (steam exploded banana fibres), the percentage crystallinity was recorded as $68.28 \%$ showing an amorphous nature at the $2 \theta$ of $21.82^{\circ}$. But after the bleaching process, the percentage crystallinity of the cellulose has increased up to $92.72 \%$ at $2 \theta$ value of $22.72^{\circ}$. It was due to more efficient removal of non-cellulosic polysaccharides and dissolution of amorphous zones [22].

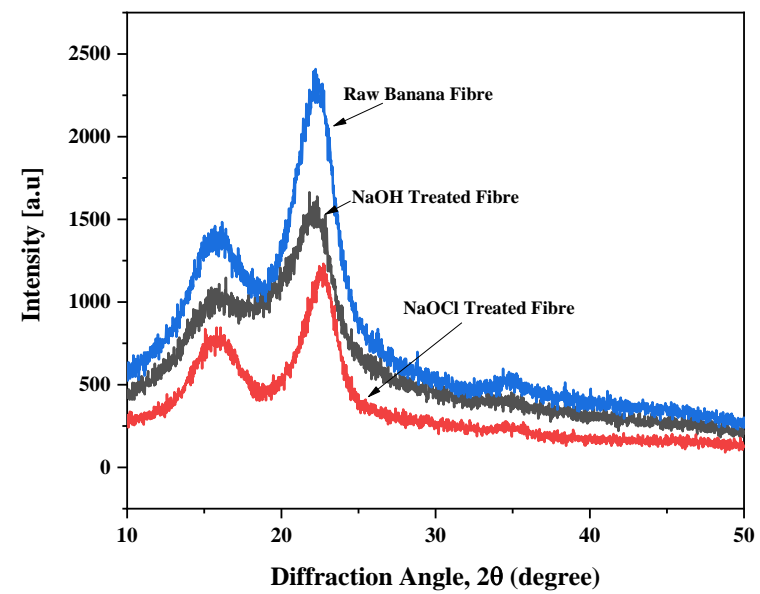

Fig. 5 XRD curves of raw, steam exploded and bleached banana fibres

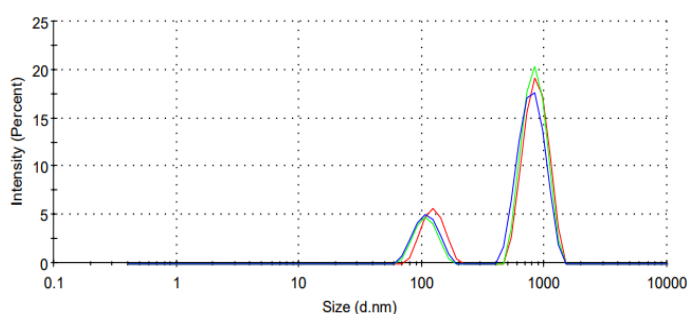

Fig. 6 Particle size distribution of CWs

According to the Fig. 6, it revealed a bimodal distribution where approximately $21 \%$ of the sample has average size of $110 \mathrm{~nm}$ and the rest has the size of $795 \mathrm{~nm}$. However, the Z-Averaged particle size was 1026.14 nm.

\subsection{Mooney Properties of Rubber Compounds}

According to the Table 5, the lowest initial Mooney Viscosity (MI), the lowest Mooney Viscosity (ML) and final Mooney Viscosity (MF) of CW/NR compound and control have been recorded. Also, the elastic coefficient (a) of $\mathrm{CW} / \mathrm{NR}$ compound is higher $(-0.28)$ than the control $(-0.25)$. Therefore, the highest processability is shown by the CW/NR composite. 
Table 5 Mooney viscosity of the control and CW/NR

\begin{tabular}{llllll}
\hline Material & MI & ML & MF & a & k \\
\hline Control & 176.66 & 91.21 & 91.21 & -0.25 & 69.23 \\
CW/NR & 115.02 & 75.45 & 75.45 & -0.28 & 58.19 \\
\hline
\end{tabular}

\subsection{Curing Characteristics}

According to the curing characteristics (Table 6), it revealed that $\mathrm{CW} / \mathrm{NR}$ composite has the highest ts2 time (122.3s), with the lowest t90 (203s), where the $90 \%$ of the cross links are created, which enables the $\mathrm{CW} / \mathrm{NR}$ composite to take the highest curing rate $\left(124.4 \mathrm{~s}^{-1}\right)$.

Table 6 Curing characteristics of rubber compounds $\left(150{ }^{\circ} \mathrm{C}, 30 \mathrm{Min}\right)$

\begin{tabular}{llllll}
\hline Material & MI $(\mathrm{dNm})$ & $\mathrm{MH}(\mathrm{dNm})$ & ts2 $(\mathrm{S})$ & t90 $(\mathrm{S})$ & Curing Rate $\left(\mathrm{S}^{-1}\right)$ \\
\hline Control & 27.2 & 105.4 & 120.6 & 297.6 & 56.5 \\
CW/NR & 24.9 & 76.1 & 122.4 & 202.8 & 124.4 \\
\hline
\end{tabular}

\subsection{Density and Hardness Properties}

After the preparation of the cured compound CW/NR composite showed the highest density of $1.13 \mathrm{~g} / \mathrm{cm}^{3}$ while it is $1.12 \mathrm{~g} / \mathrm{cm}^{3}$ in the control. Both compounds had its Shore A hardness values as 68 nevertheless the lowest rebound resilience (53) showed in CW/NR composite and it was 58 in the control. However, the both materials were in the desired range of the respected tyre compound properties.

\subsection{Tensile Properties}

An improved tensile strength has been recorded in the CW/NR composite (245.12 $\mathrm{MPa}$ ) compared to the control (158.68 $\mathrm{MPa})$. The modulus at $300 \%$ level is inferior in CW/NR compound. However, CW/NR composite showed the superior elongation at break (425\%) at the same time and it was $331.15 \%$ in the control (Table 7).

Table 7 Modulus 300\%, tensile, tearing, abrasion

\begin{tabular}{lcllll}
\hline Material & $\begin{array}{l}\text { Modulus } \\
300 \%(\mathrm{MPa})\end{array}$ & $\begin{array}{l}\text { Tensile } \\
(\mathrm{MPa})\end{array}$ & $\begin{array}{l}\text { Elongation } \\
\text { at break\% }\end{array}$ & $\begin{array}{l}\text { Tearing } \\
(\mathrm{N} / \mathrm{mm})\end{array}$ & $\begin{array}{l}\text { Abrasion Volume } \\
\text { loss }\left(\mathrm{mm}^{3}\right)\end{array}$ \\
\hline Control & 177.6 & 209.7 & 331.1 & 47.3 & 99.0 \\
CW/NR & 158.6 & 245.1 & 425.0 & 37.1 & 110.0 \\
\hline
\end{tabular}

After taking the abrasion volume loss, CW/NR was inferior because it showed $110 \mathrm{~mm}^{3}$ abrasion volume loss. However, the control showed the abrasion volume lose as $99 \mathrm{~mm}^{3}$ nominating the control as the superior at abrasion resistance. Surprisingly, both materials showed the less tearing values but from that the control was the superior marking its tearing value as $47.43 \mathrm{~N} / \mathrm{mm}$.

\subsection{Cut and Chip Properties}

According to the results of cut and chip test, it revealed that CW/NR compound has superior properties than the control in both percentage weight loss and averaged percentage diameter loss (Table 8)

Table 8 Averaged percentage weight loss and averaged percentage diameter loss

\begin{tabular}{lll}
\hline Material & Percentage Weight loss (\%) & Percentage Diameter loss (\%) \\
\hline Control & 11.5 & 14.4 \\
CW/NR & 9.3 & 12.5 \\
\hline
\end{tabular}

\section{Conclusion}

In summary, CWs were extracted from banana pseudo-stem suggesting that the under-utilized banana pseudo-stem waste can be effectively utilized by extracting cellulose from its ligno-cellulosic biomass by steam explosion technique. Both FTIR and XRD studies conformed the structure of cellulose as well as its purification trends. Also, from the particle size analysis, it showed that a proportion of CWs was almost in the nano scale. The prepared CWs were incorporated at 3 phr of loading level with diluted centrifuged latex. From the Mooney properties of the raw materials, it showed that $\mathrm{CW} / \mathrm{NR}$ composite had the higher processability over the control. By considering the physio-mechanical properties such as modulus at $300 \%$, tensile strength and cut and chip values concluded that the cellulose whiskers have a potential to slightly replace CB in tyre tread manufacturing.

\section{References}

[1] E. Trovatti, A.J.F. Carvalho, S.J.L. Ribeiro, A. Gandini, Simple green approach to reinforce natural rubber with bacterial cellulose nanofibres, Biomacromol. 14 (2013) 2667-2674.

[2] L. Bokobza, J.P. Chauvin, Reinforcement of natural rubber: use of in situ generated silicas and nanofibres of sepiolite, Polym. 46 (2005) 4144-4151.

[3] C. Li, F. Huang, J. Wang, X. Liang, S. Huang, J. Gu, Effects of partial replacement of carbon black with nanocrystalline cellulose on properties of natural rubber nanocomposites, J. Polym. Eng. 38 (2018) 137-146.

[4] S. Xu, J. Gu, Y. Luo, D. Jia, Effects of partial replacement of silica with surface modified nanocrystalline cellulose on properties of natural rubber nanocomposites, Express. Polym. Lett. 6 (2012) 14-25.

[5] T. Kirushanthi, T. Etampawala, D. Edirisinghe, J. Pitawala, D. R. Ratnaweera Development of agro-industrial waste reinforced natural rubber composite: A Potential formulation for rubber flooring product, J. Adv. Che. Sci. 4 (2018) 571-575.

[6] Y.G. Kondarage, H.M.J.C. Pitawala, T. Kirushanthi, D. Edirisinghe, T. Etampawala, Ceramic waste-based natural rubber composites: An exciting way for improving mechanical properties, J. Adv. Che. Sci. 4 (2018) 576-582.

[7] M.J. John, K. Varughese, S. Thomas, Green composites from natural fibres and natural rubber: effect of fibre ratio on mechanical and swelling characteristics, J. Nat. Fibres 5 (2008) 47-60.

[8] J. Bras, M.L. Hassan, C. Bruzesse, E.A. Hassan, N.A. El-Wakil, A. Dufresne, Mechanical, barrier, and biodegradability properties of bagasse cellulose whiskers reinforced natural rubber nanocomposites, Ind. Crops Prod. 32 (2010) 627-633.

[9] D. Pasquini, E. De Morais Teixeira, A.A. Da Silva Curvelo, M.N. Belgacem, A. Dufresne, Extraction of cellulose whiskers from cassava bagasse and their applications as reinforcing agent in natural rubber, Ind. Crops Prod. 32 (2010) 486-490.

10] P. Visakh, S. Thomas, K. Oksman, A.P. Mathew, Crosslinked natural rubber nanocomposites reinforced with cellulose whiskers isolated from bamboo waste: Processing and mechanical/thermal properties, Composites A.: Appl. Sci. Manuf. 43 (2012) 735-741.

[11] A. Dufresne, Processing of polymer nanocomposites reinforced with polysaccharide nanocrystals, Molecules 15 (2010) 4111-4128.

[12] N. Venkateshwaran, A. Elayaperumal, Banana fibre reinforced polymer composites-a review, J. Reinf. Plast. Composites 29 (2010) 2387-2396.

13] M.Z. Hassan, S. Sapuan, S.A. Roslan, S. Sarip, Optimization of tensile behavior of banana pseudo-stem (Musa acuminate) fibre reinforced epoxy composites using response surface methodology, J. Mater. Res. Tech. 8 (2019) 3517-3528.

[14] M. Barsbay, O. Güven, Surface modification of cellulose via conventional and controlled radiation-induced grafting, Radiat. Phys. Chem. 160 (2019) 1-8.

[15] S. Gopi, P. Balakrishnan, D. Chandradhara, D. Poovathankandy, S. Thomas, General scenarios of cellulose and its use in the biomedical field, Mater. Today Chem. 13 (2019) 59-78.

[16] A. Pappu, V. Patil, S. Jain, A. Mahindrakar, R. Haque, V.K. Thakur, Advances in industrial prospective of cellulosic macromolecules enriched banana biofibre resources: A review, Int. J. biol. Macromol. 79 (2015) 449-458.

[17] C. Vigneswaran, V. Pavithra, V. Gayathri, K. Mythili, Banana fibre: scope and value-added product development, J. Text. Appar. Tech. Manag. 9 (2015) 1-7.

[18] B.M. Cherian, L.A. Pothan, T. Nguyen-Chung, G.N. Mennig, M. Kottaisamy, S Thomas, A novel method for the synthesis of cellulose nanofibril whiskers from banana fibres and characterization, J. Agric. Food Chem. 56 (2008) 5617-5627.

[19] N. Kruer-Zerhusen, B. Cantero-Tubilla, D.B. Wilson, Characterization of cellulose crystallinity after enzymatic treatment using Fourier transform infrared spectroscopy (FTIR), Cellul. 25 (2018) 37-48.

[20] A.N. Benítez, M.D. Monzón, I. Angulo, Z. Ortega, P.M. Hernández, M.D. Marrero Treatment of banana fibre for use in the reinforcement of polymeric matrices, Measure. 46 (2013) 1065-1073.

[21] F. Meng, G. Wang, X. Du, Z. Wang, S. Xu, Y. Zhang, Extraction and characterization of cellulose nanofibres and nanocrystals from liquefied banana pseudo-stem residue, Composites Part B: Engineering, 160 (2019) 341347.

[22] S. Elanthikkal, U. Gopalakrishnapanicker, S. Varghese, J.T. Guthrie, Cellulose microfibres produced from banana plant wastes: Isolation and characterization, Carbohydr. Polym. 80 (2010) 852-859. 